\title{
Contenido de trabajo en las exportaciones manufactureras mexicanas, 2008 y 2012
}

\author{
Gerardo Fujii G., Rosario Cervantes $M$. \\ y Ana Sofía Fabián R.
}

RESUMEN

En este trabajo se presenta una estimación del número de puestos de trabajo contenidos en las exportaciones manufactureras mexicanas en 2008 y 2012, basada en las matrices de insumo-producto elaboradas por el Instituto Nacional de Estadística y Geografía (INEGI). Se presentan los datos de trabajo directo (el necesario para producir los bienes exportados) e indirecto, es decir, el trabajo contenido en los insumos nacionales incorporados en las exportaciones, más el empleo generado por todas las repercusiones indirectas derivadas de la producción de los bienes intermedios que se incorporan en ellas. El empleo en las exportaciones se desagrega por sectores manufactureros exportadores y por sectores donde el empleo es creado. Dado que cualquier sector exportador requiere bienes intermedios que se producen en el mismo sector o en otros, el trabajo indirecto contenido en las exportaciones es dividido entre empleo indirecto intrasectorial e intersectorial.

PALABRAS CLAVE

CLASIFICACIÓN JEL

AUTORES
Creación de empleos, medición, empresas industriales, productos manufacturados, exportaciones, estadísticas del empleo, México

F14, F16, F19

Gerardo Fujii G. es Profesor titular en la Facultad de Economía de la Universidad Nacional Autónoma de México. fujii@unam.mx

Rosario Cervantes M. es Profesora asociada en el Centro Universitario de Ciencias Económico Administrativas de la Universidad de Guadalajara, México. mariac@cucea.udg.mx

Ana Sofía Fabián R. es Profesora de asignatura en la Facultad de Economía de la Universidad Nacional Autónoma de México. asfr12@gmail.com 


\section{I}

\section{Introducción}

Desde fines de la década de 1980, en México se emprendieron reformas estructurales profundas, una de las cuales fue la liberalización comercial, que fue reduciendo el régimen de protección a las actividades económicas internas. Esto condujo, inevitablemente, a la desaparición de las actividades que no estuvieran en condiciones de competir con las importaciones, lo que sería compensado, según se esperaba, con el vuelco hacia el exterior de las ramas productivas en las que el país tiene ventajas comparativas. La reforma comercial se concretó con la adhesión del país al Acuerdo General sobre Aranceles Aduaneros y Comercio (GATT) en 1987, y la entrada en vigor de Tratado de Libre Comercio de América del Norte en 1994, con el que se procuraba alentar las exportaciones, en particular las dirigidas a los Estados Unidos de América. El objetivo último de esta transformación era dinamizar el crecimiento económico y generar más empleos. Con respecto a este último punto, dada la abundancia relativa de trabajo en México, sobre la base de los planteamientos de Heckscher-Ohlin, se esperaba que la ventaja comparativa del país se concentrara en productos intensivos en trabajo relativamente poco calificado, por lo que la dinamización de las exportaciones debería repercutir con fuerza en el empleo.

En el momento de la discusión de los términos del Tratado de Libre Comercio de América del Norte (TLCAN), en los Estados Unidos de América tuvo lugar una intensa polémica sobre los efectos en el empleo que la liberalización tendría en ese país. Algunos argumentaron que la posibilidad de producir en México con costos laborales relativamente bajos para exportar a los Estados Unidos de América sin barreras comerciales conduciría a que los capitales se desplazaran hacia México, con los consiguientes efectos negativos, en un caso, y positivos, en el otro, sobre el empleo. Además, dado que la ventaja comparativa de México radica en productos intensivos en trabajo poco calificado, ello conduciría a que la relación entre los salarios de los trabajadores poco calificados y los salarios de los trabajadores calificados experimentara una caída, contribuyendo a profundizar la desigualdad en el reparto del ingreso en los Estados

$\square$ Los autores agradecen los comentarios de un árbitro anónimo que permitieron enriquecer este trabajo.
Unidos de América. La otra posición insistía en que la liberalización comercial conduciría a la expansión de las exportaciones en los dos países, de tal manera que los efectos negativos en el empleo derivados de las mayores importaciones serían compensados por los efectos positivos de las exportaciones (en Hufbauer y Schott (1993) se revisa, en los años de la discusión del acuerdo, la literatura sobre sus repercusiones en el mercado laboral de los Estados Unidos de América). En contraste, en México dominaba un ambiente optimista sobre los beneficios que en términos de crecimiento y empleo se derivarían del acuerdo comercial con los Estados Unidos de América (véase, por ejemplo, Lustig, Bosworth y Lawrence, 1993).

La liberalización comercial se ha expandido por todo el mundo, lo que ha motivado numerosas investigaciones destinadas a evaluar sus efectos laborales. Entre los temas investigados, se pueden destacar tres: i) exportaciones y creación de empleo; ii) importaciones y destrucción de empleo, y iii) efectos del incremento del comercio exterior en los salarios y la distribución del ingreso. Este estudio se focaliza en la primera línea de investigación.

El objetivo del trabajo es presentar una estimación de la cantidad de empleo (medida en puestos de trabajo) contenida en las exportaciones manufactureras de México. Para producir el bien exportado se requiere desplegar trabajo, que —en la terminología que aquí se empleaes el trabajo directo contenido en las exportaciones. Además, la producción de exportaciones requiere de materias primas, insumos, partes y componentes, cuya producción, si es de origen nacional, determina el trabajo nacional indirecto contenido en las exportaciones. En la medida en que la interconexión entre las actividades directamente exportadoras y el resto de la economía sea más intensa, el trabajo indirecto contenido en las exportaciones será más elevado. Las materias primas requeridas para producir las exportaciones pueden ser elaboradas por actividades incluidas en el mismo sector que exporta o por otros sectores. El empleo contenido en las primeras es trabajo indirecto intrasectorial y, el segundo, trabajo indirecto intersectorial. Además, dado que la producción de manufacturas para la exportación requiere de insumos tanto de origen manufacturero como no manufacturero, las exportaciones manufactureras generan empleo indirecto tanto en la manufactura como 
en sectores no manufactureros. Para la estimación del efecto que tienen las exportaciones en el uso del factor trabajo se han aplicado tres métodos: regresiones, que es la técnica empleada con más frecuencia; el de contenido de factores en el comercio (Wood, 1994), y el basado en matrices de insumo-producto. El hecho de que en los años recientes se hayan publicado matrices de insumo-producto homologadas para diversos países, ha posibilitado estimaciones sobre el empleo contenido en las exportaciones basadas en dichas matrices para varios países.

De acuerdo con el método adoptado en este trabajo, aquí solo se hará referencia a los trabajos que emplean este método. La bibliografía sobre el tema se ha expandido en forma exponencial en los últimos tres años, como lo muestra el siguiente listado parcial de trabajos: Irawan y Welfens (2014), sobre los posibles efectos para Alemania, la Unión Europea y los Estados Unidos de América del acuerdo sobre comercio e inversiones entre los Estados Unidos de América y la Unión Europea que está en discusión; Kupfer y otros (2013) para el Brasil; Chen y otros (2012) y Los, Timmer y De Vires (2012) para la economía china; Sousa y otros (2012) para la economía de la Unión Europea; Aswicahyono, Brooks y Manning (2011) para Indonesia; Brautzsch y Ludwig (2011) y Lurweg, Oelgemöller y Westermeier (2010) para la economía alemana; Koller y Stehrer (2010) para Austria; y Kiyota (2011) para el Japón.

Con respecto a México, este método se ha empleado para investigar el tema de las exportaciones y el empleo en tres trabajos: Ruiz-Nápoles (2004); Cardero y Aroche (2008), y Cervantes y Fujii (2012). Aunque estos tres trabajos tienen en común que cubren largos períodos, que van desde las últimas décadas del siglo pasado hasta los primeros años de este siglo, y están inspirados por el objetivo común de conocer los efectos de la liberalización comercial en el empleo, sus objetivos precisos no son exactamente coincidentes. Si el texto de Cardero y Aroche (2008) se centra en el cálculo desagregado por sectores de la evolución de los coeficientes y multiplicadores de empleo, en el marco de la liberalización comercial y de la dinamización y el cambio en la composición de las exportaciones, el de Ruiz-Nápoles procura, en el plano del empleo, estimar la proporción de los puestos de trabajo creados en el período analizado que corresponde a empleo generado por las exportaciones y por el mercado interno. Cabe destacar que en este estudio, el trabajo contenido en las exportaciones es dividido entre empleo directo e indirecto. Por último, el trabajo de Cervantes y Fujii (2012), aparte de calcular en números absolutos el empleo total — directo e indirecto — contenido en las exportaciones del país, presenta una estimación, con supuestos que pueden ser considerados muy restrictivos, del empleo contenido en las importaciones del país, para llegar al balance neto de los efectos de la apertura comercial en el número de puestos de trabajo.

Las diferencias entre los tres trabajos mencionados en que se estima el efecto de la liberalización comercial en el empleo en México y la presente investigación son las siguientes: primero, aquí se pone el foco en dos años (2008 y 2012); en segundo término, se aplica la matriz simétrica doméstica de insumo-producto a 79 subsectores de actividad económica elaborada por el Instituto Nacional de Estadística y Geografía (INEGI). En los trabajos anteriores se utilizaron las matrices creadas por el INEGI para 1980 y 1985, en tanto que los datos de los años sucesivos provinieron de Stata Matrix, producida por Consultoría Internacional Especializada, S.A., a partir de la extrapolación de las matrices de los años ochenta; en tercer lugar, el cálculo del contenido de empleo en las exportaciones se concentra en aquellas de origen manufacturero en virtud de que constituyen el $80 \%$ del total de las exportaciones del país. Por último, el empleo indirecto contenido en las exportaciones manufactureras se divide entre intra e intersectorial. Hasta donde se tiene conocimiento, este es el primer trabajo en que se introduce esta distinción en el contenido de empleo indirecto en las exportaciones.

El tema del trabajo es relevante dada la magnitud del desafío que en el plano del empleo sigue enfrentando la economía mexicana, según queda ilustrado por el hecho de que, en 2012, el 60\% de los ocupados laboraba en situación informal, mientras que los contratados en condiciones informales en el sector formal de la economía representaban el $31 \%$ del total de ocupados, y los que lo hacían en la economía informal "propiamente tal" alcanzaban al 29\% de los ocupados (INEGI, 2012). Los diversos sectores exportadores se caracterizan por tener intensidades laborales y relaciones entre trabajo directo e indirecto contenido en las exportaciones diferentes, por lo que el conocimiento de las características ocupacionales de las exportaciones puede contribuir a dirigir la política exportadora para maximizar sus efectos en la creación de empleo.

El presente trabajo se estructura de la siguiente manera: en la sección II se ofrece una breve descripción del notable dinamismo y las profundas transformaciones que ha mostrado el sector exportador de México durante el último cuarto de siglo. En la sección III se presenta el método de estimación y en la sección IV se exponen los resultados empíricos de la investigación. El artículo finaliza en la sección $\mathrm{V}$ con sus principales conclusiones. 


\section{II \\ Dinamismo y transformaciones de las exportaciones mexicanas}

Entre 1992 y 2012, el total de las exportaciones del país se expandió en forma notable, pasando de algo menos de 50 mil millones de dólares a unos 375 mil millones en un período de 16 años. Esto condujo al marcado incremento del coeficiente de exportaciones, que pasó de un $13 \%$ a más del $30 \%$ entre esos años (Banco de México, 2013).

El dinamismo exportador del país fue simultáneo a la modificación en la composición de las exportaciones de bienes, de tal manera que en 2013 las de origen manufacturero representaban el $84 \%$ del total de las exportaciones del país (INEGI, 2014).

La clasificación de las exportaciones industriales por intensidad factorial entre productos intensivos en recursos naturales o en tecnología - ya sea baja, media o alta- muestra que, en 2012, el peso decisivo les correspondió a los productos industriales intensivos en tecnología media y alta, que representaron el $62 \%$ de las exportaciones industriales del país (Naciones Unidas, 2014). Sin embargo, estos datos deben considerarse

\section{III}

\section{Metodología}

Si se supone que en las técnicas de producción no hay diferencias significativas entre los bienes que se exportan y los destinados al mercado interno, el producto asociado a las exportaciones se expresa como:

$$
x_{e}^{d}=\left(I-A^{d}\right)^{-1} f^{e}
$$

donde $x_{e}^{d}$ es el vector del total de producción (directa e indirecta) asociado a las exportaciones, $f^{e}, \mathrm{y}\left(I-A^{d}\right)^{-1}$ es la matriz inversa de Leontief, siendo $I$ la matriz identidad de dimensión $n \times n$, en que $n$ es el número de sectores de la economía, y $A^{d}$ la matriz de coeficientes técnicos.

El total de empleo, directo e indirecto, generado por las exportaciones $\left(l_{e}\right)$ se obtiene al multiplicar el vector de coeficientes de trabajo $(\lambda)$ por el valor bruto de producción asociado a los bienes exportados: con cuidado, pues se derivan de la clasificación de las exportaciones por nivel tecnológico y bien puede ocurrir que un país esté especializado en la fase de producción tecnológicamente simple de un producto que es de elevada tecnología. Esto es sobre todo importante de tener en cuenta en países en los que una parte significativa de las exportaciones manufactureras se genera en el marco de cadenas globales de valor, en las que México participa intensamente. En 2003, el 62\% de las exportaciones manufactureras del país tenía su origen en la industria maquiladora (Cervantes y Fujii, 2012, pág. 152). Este dato es relevante de considerar con respecto al tema de este trabajo por dos razones: en primer lugar, porque la posición de México en el marco de estas cadenas se ubica en los procesos intensivos en trabajo, de modo que se puede esperar que la manufactura integrada en cadenas de valor sea generadora de empleo directo. Por otra parte, estas actividades se caracterizan por ser intensivas en importaciones, pudiendo esperarse que el empleo indirecto que crean no sea especialmente elevado.

$$
\begin{gathered}
l_{e}=\lambda \hat{X}_{e} \\
\lambda=\left\{l_{j} / x_{j}\right\}
\end{gathered}
$$

donde $\lambda$ es el vector fila de coeficientes de empleo por sector, cuyos elementos típicos se obtienen al dividir el total de puestos de trabajo en el sector $j\left(l_{j}\right)$ por el valor total de la producción del mismo sector $\left(x_{j}\right)$, y es la matriz diagonalizada del producto bruto generado por las exportaciones $\left(x_{e}^{d}\right)$.

El empleo directo generado por las exportaciones $\left(l d_{e}\right)$ se obtiene al multiplicar el vector de coeficientes de empleo por la matriz diagonalizada del valor de las exportaciones, $\hat{E}$. 


$$
l d_{e}=\lambda \hat{E}
$$

El empleo indirecto, por sector de origen de los insumos nacionales, generado por las exportaciones es igual a:

$$
l i_{e}=l_{e}-l d_{e}
$$

Finalmente, para descomponer el empleo que, de manera indirecta, genera un sector exportador en el resto de los sectores, en la ecuación (6) se presenta la matriz de empleo indirecto por sectores de origen y destino de los insumos nacionales incorporados en las exportaciones:

$$
l i_{e}=\left[\hat{\lambda}\left(I-A^{d}\right)^{-1} \hat{E}\right]
$$

donde $\hat{\lambda}$ y $l d_{e}$ son las matrices diagonalizadas de los coeficientes técnicos de empleo $(\lambda)$ y del empleo directo $\left(l d_{e}\right)$, respectivamente. Siendo la matriz de empleo indirecto $\left(l i_{e}\right)$ una matriz de orden $n$, los elementos en su diagonal principal representan el empleo indirecto intrasectorial, esto es, cuando el sector de origen de los insumos intermedios es el mismo sector de destino $(i=j)$. Todos los elementos que no se encuentren sobre la diagonal principal representan los volúmenes de empleo indirecto derivados de las relaciones intersectoriales, cuando el sector de origen de los insumos es diferente del sector de destino $(i \neq j)$.

Las principales limitaciones del método empleado se derivan del nivel de agregación de información por rama de actividad económica y del supuesto de una función de producción de proporciones fijas que, a través de la inversa de Leontief, podrían conducir a sobrestimar los puestos de trabajo asociados a la actividad exportadora, ignorando la posibilidad de contar con economías de escala en algunas empresas (grandes). Por otra parte, al no considerar que cada nuevo puesto de trabajo que se genera tiene un efecto positivo en la demanda final interna, se subestima el efecto que tienen las exportaciones en la generación de empleo.

\section{IV}

\section{Trabajo total, directo e indirecto, en las exportaciones manufactureras}

En el cuadro A.1 del anexo se muestra el contenido de trabajo en las exportaciones manufactureras mexicanas en 2012. En la lectura vertical del cuadro A.1 se aprecia, para cada uno de los sectores que encabezan las columnas, el total de puestos de trabajo - directo e indirecto- dividido entre intra e intersectorial, contenido en sus exportaciones, así como su distribución por sectores en los que se crea. La lectura horizontal indica, para cada uno de los sectores señalados en las filas, el total del trabajo de cada sector generado por las exportaciones manufactureras, su descomposición entre directo e indirecto, intra e intersectorial, y su distribución según los sectores exportadores que lo generan. En las dos últimas filas y columnas del cuadro A.1 se observa la distribución por sectores del total del empleo creado por las exportaciones manufactureras. Las filas presentan el empleo total contenido en las exportaciones de los sectores manufactureros que encabezan las columnas y la participación de estos en el total del empleo contenido en las exportaciones de la manufactura. Por su parte, los datos de las últimas columnas señalan los sectores en que se genera el empleo contenido en las exportaciones manufactureras y su distribución según los sectores manufactureros exportadores que los generan.

El total de trabajo, directo e indirecto, contenido en las exportaciones manufactureras asciende a 3.892.269 puestos de trabajo, equivalentes al 9,2\% del total de los puestos reportados por la matriz de insumoproducto de 2012. Por otra parte, la suma del empleo directo más indirecto intrasectorial (1 millón 966 mil puestos de trabajo) contenido en las exportaciones manufactureras representa el 36,5\% de los puestos de trabajo manufactureros reportados por la matriz. Los datos de 2008 ascienden a 3 millones 633 mil puestos de trabajo en las exportaciones manufactureras $(7,7 \%$ de los puestos de ese año, mientras que el empleo directo más el indirecto intrasectorial (1 millón 707 mil puestos de trabajo) equivalen al 30\% del trabajo manufacturero. Por lo tanto, la proporción del empleo manufacturero derivado de las exportaciones de la manufactura es significativa y ascendente. 
Puede verse que casi todas las celdas del cuadro A.1 están rellenas, pero que - en la mayor parte de los casos- el empleo generado en los sectores por la rama manufacturera directamente exportadora es poco importante. Con el fin de mostrar las relaciones sectoriales más relevantes en términos de empleo, en el cuadro 1 se muestra la misma matriz de datos conservando los datos superiores al 0,3\% del total del empleo contenido en las exportaciones (11.677 puestos de trabajo). Puede verse que de las 1.659 celdas que contiene la matriz, solo en 49 de ellas el empleo exportador supera el límite fijado. La suma del empleo contenido en estas celdas equivale a 2.840 .339 puestos de trabajo ( $73 \%$ del total del empleo contenido en las exportaciones manufactureras). En el cuadro A. 2 se entrega esta información respecto de 2008 con el mismo filtro porcentual (10.899 empleos). Los cambios más importantes que se han registrado entre 2008 y 2012 son los siguientes:

i) El número de celdas con cómputos pasa de 54 a 49, lo que significa que se ha debilitado la capacidad de las exportaciones manufactureras de generar empleos en otros sectores de la economía por sobre el límite establecido.

ii) Si en 2008, de las 21 ramas de la industria manufacturera, las exportaciones de 20 sectores generaban más de un $0,3 \%$ del total del empleo manufacturero exportador, ya sea por vía intra o intersectorial, en 2012 aquellas ramas se redujeron a 18 (en 2008 solo estaba excluida la rama 23: Derivados del petróleo y el carbón; a la que en 2012 se añadieron la 20: Industria de la madera, y la 22: Impresiones).

iii) Sin embargo, entre los años considerados se incrementó en un $7 \%$ el total del empleo generado por las exportaciones manufactureras, lo que significa que se ha diversificado intra e intersectorialmente la capacidad de la industria manufacturera de generar empleo en cantidades inferiores al 0,3\% del empleo contenido en estas exportaciones.

\section{Trabajo creado por las exportaciones manufactureras según sectores que lo contienen y sectores en los que se genera}

En el cuadro 2 se ha hecho una selección de los principales sectores del cuadro 1 de acuerdo con la cantidad de empleo contenido en y generado por las exportaciones para el año 2012. Los sectores manufactureros creadores de empleo seleccionados son los que aportan más del 5\% del total del empleo contenido en las exportaciones manufactureras. A su vez, los sectores en que se genera el empleo son los que superan el 4,6\% del total.

Se observa que de los 21 sectores manufactureros de la matriz, 6 son los que crean más empleo de los límites expuestos en el párrafo anterior. Por otra parte, de los 79 sectores de la matriz, solo 7 superan el 4,6\% del total del empleo manufacturero exportador.

Las filas del cuadro 2 señaladas en cursivas muestran: i) los datos concentrados del empleo total contenido en las exportaciones de los sectores manufactureros que encabezan las columnas; ii) el porcentaje que cada sector representa en el total del empleo contenido en las exportaciones; iii) la participación del empleo contenido en las exportaciones con respecto al total del empleo sectorial; iv) la descomposición del empleo entre directo e indirecto y de este último entre intra e intersectorial; v) el coeficiente sectorial de empleo (número de puestos de trabajo por un millón de pesos de producción bruta), y vi) el porcentaje con que cada sector contribuye a las exportaciones manufactureras. En las subsecciones 2 y 3 que siguen se volverá a los datos de descomposición del empleo entre directo e indirecto y de coeficiente del empleo, de modo que la siguiente descripción se concentrará en la información restante incluida en el cuadro 2.

El empleo contenido en las exportaciones de estos seis sectores manufactureros representa el $70 \%$ del total, y sus exportaciones el $77 \%$ de las de origen manufacturero.

Puede verse que son las exportaciones de equipo de transporte (28\% de las exportaciones manufactureras) las que más empleo contienen ( $25 \%$ del total), seguidas por las de la industria electrónica ( $12 \%$ del empleo), aunque su aporte a las exportaciones manufactureras es inferior solo algunos puntos $(26 \%)$. El tercer puesto lo ocupa el sector de equipo eléctrico (8,4\% en exportaciones y 7,6\% del empleo contenido en ellas). El que en los sectores de equipo de transporte y eléctrico no haya una diferencia importante en cuanto a su participación en las exportaciones y el empleo, y que esto sí ocurra en la industria electrónica, se deriva del hecho de que los coeficientes de empleo (número total de empleos por un millón de pesos de valor bruto de la producción) de los dos primeros sectores son iguales a uno, mientras que el de equipo electrónico es sensiblemente más bajo $(0,5)$.

Solo en un sector, la industria alimentaria, la participación en términos de empleo contenido en las exportaciones manufactureras es sensiblemente superior a su aporte en cuanto a exportaciones $(2,8 \%$ de las exportaciones manufactureras y $11 \%$ del empleo contenido en las exportaciones manufactureras). Esto resulta del hecho de que este sector se caracteriza por un coeficiente de empleo elevado $(4,2)$. 


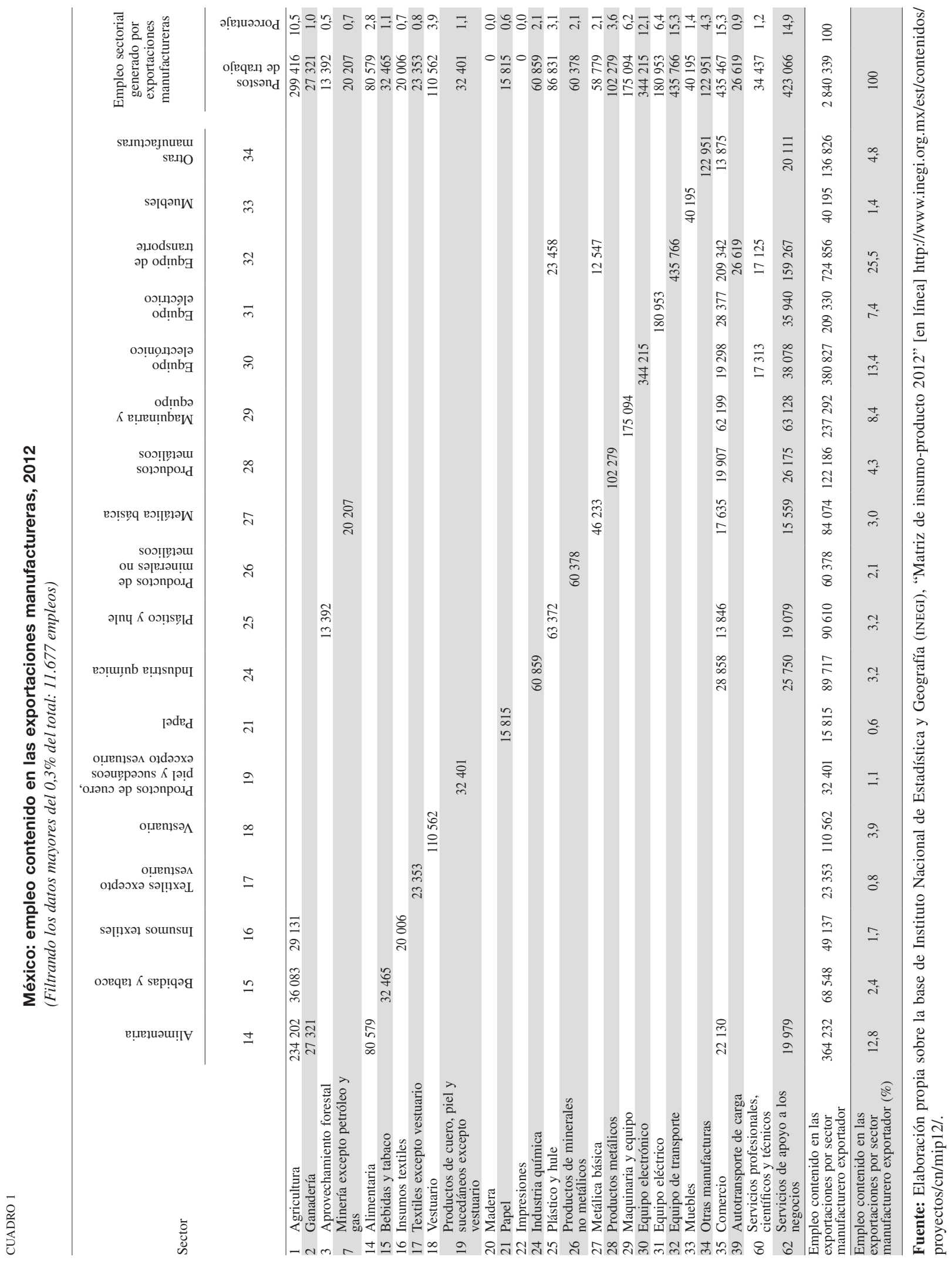




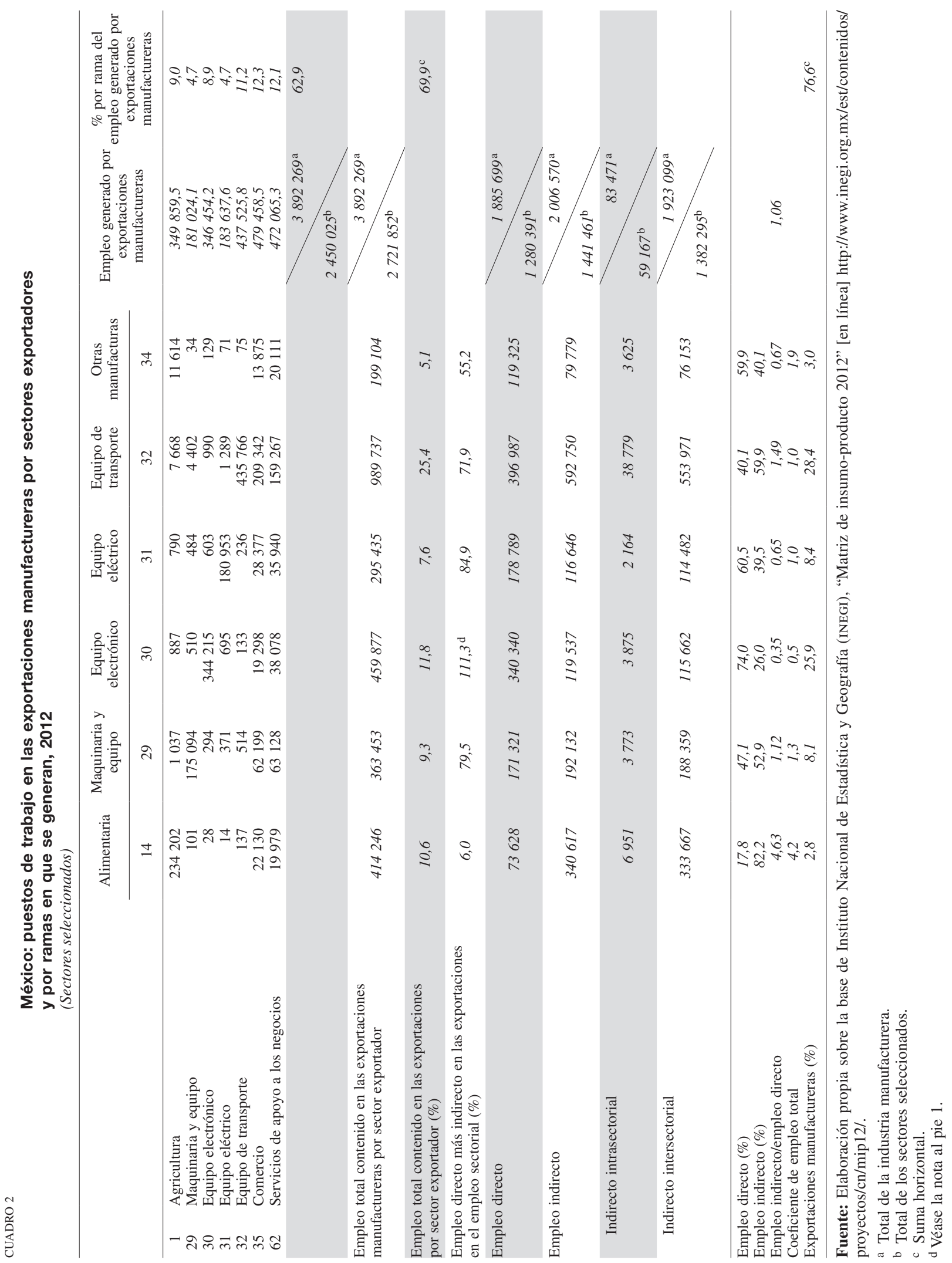


La suma de los puestos de trabajo directos e indirectos intrasectoriales contenidos en las exportaciones de algunos de estos sectores (maquinaria y equipo, electrónica ${ }^{1}$, equipo eléctrico y de transporte) representa más del $70 \%$ de los ocupados en ellos.

En las dos últimas columnas del cuadro 2 se aprecian los siete sectores más importantes debido al empleo generado por las exportaciones manufactureras, que representa el $63 \%$ del empleo total contenido en ellas. La mayor parte del empleo $(29,5 \%)$ creado por las exportaciones manufactureras se genera en la misma manufactura: $11 \%$ en la rama de equipo de transporte; $9 \%$ en la de electrónica, y 4,7 \% en las de maquinaria y equipo eléctrico. Pero dado que las exportaciones manufactureras también demandan insumos producidos en otros sectores, son importantes generadoras de empleo en los sectores de comercio y de servicios de apoyo a los negocios. Por último, el $9 \%$ del empleo generado por las exportaciones manufactureras se crea en la agricultura, especialmente por las de la industria alimentaria.

En el cuadro A.3 se muestra la misma información para el año 2008. La comparación de los datos de este cuadro con los del cuadro 2 , que presenta la información correspondiente a 2012, permite llegar a las siguientes conclusiones:

i) Entre 2008 y 2012, el número de sectores manufactureros que más ponderación tienen en el empleo contenido en las exportaciones de la manufactura se reduce de siete a seis (quedan excluidos el del vestuario y el de productos metálicos y se añade el de otras manufacturas). El número de sectores en los que la exportación manufacturera genera empleo por sobre la marca establecida pasa de seis a siete (se añade el sector de maquinaria y equipo).

ii) Estos sectores manufactureros exportadores contribuyeron con el $77,5 \%$ de las exportaciones manufactureras en 2008, con el 76,6\% en 2012 y con el $72 \%$ y el $70 \%$ del empleo contenido en las exportaciones manufactureras, respectivamente.

iii) El empleo contenido en las exportaciones manufactureras de estos sectores pasa de 2,62 millones a 2,72 millones. Por sectores manufactureros exportadores, los cambios más relevantes son los siguientes: aumento en el empleo contenido en las

\footnotetext{
1 Para este sector, el dato de $112 \%$ se deriva de la información de la matriz de 2012 según la cual la demanda final del sector supera a sus exportaciones. Esta incoherencia podría provenir del hecho de que la discrepancia estadística reportada por la matriz es muy significativa ( $17 \%$ de las exportaciones). Sin embargo, la matriz no es explícita sobre este punto.
}

exportaciones de la industria alimentaria (de 296.000 a 414.000 puestos de trabajo); en las de maquinaria y equipo (de 254.000 a 363.000 puestos) y en las de equipo de transporte (de 776.000 a 990.000 puestos de trabajo). Esto fue compensado por el descenso en los puestos de trabajo contenidos en las exportaciones de equipo eléctrico (de $330.000 \mathrm{a}$ 295.000 puestos) y electrónico (de 582.000 a 460.000 puestos de trabajo) ${ }^{2}$. Por último, la desaparición de los sectores del vestuario y de productos metálicos de los sectores exportadores con mayor contenido de empleo se explica por su descenso de 198.000 a 110.000 (puestos de trabajo) (véase el cuadro 1) en el primer caso y de 192.000 a 122.000 puestos en el segundo, mientras que la incorporación de empleo contenido en las exportaciones de otras manufacturas a los sectores seleccionados fue determinada por el incremento de 149.500 a 199.000 en el número de puestos de trabajo que ellas contienen.

iv) $\mathrm{Si}$ en 2008 eran tres los sectores manufactureros en que el empleo directo más el indirecto intrasectorial superaban el $70 \%$ de los puestos de trabajo contenidos en ellos, en 2012 se les añade el de equipo de transporte.

v) El empleo generado por las exportaciones manufactureras en los sectores seleccionados pasa de 2,19 millones a 2,45 millones, aumentando significativamente el empleo agrícola y el de las ramas de equipo eléctrico y de transporte contenidos en las exportaciones manufactureras, mientras que cae el empleo en los sectores de equipo electrónico y de comercio generado por ellas.

\section{Empleo directo e indirecto contenido en las exportaciones}

De los 3,9 millones de empleos contenidos en las exportaciones, el empleo directo asciende a 1,9 millones (48\%), mientras que el resto -2 millones de empleosconstituye empleo indirecto. En segundo término, la selección de celdas del cuadro 1 con datos superiores al 0,3\% del empleo total contenido en las exportaciones manufactureras (11.677 empleos) deja ver que en todos los sectores manufactureros que allí se identifican, el empleo directo más el indirecto intrasectorial superan este límite, mientras que muy pocas celdas que están fuera de la diagonal, indicativas de la creación de empleo indirecto intersectorial, están llenas. La gran cantidad

\footnotetext{
2 Este dato contiene una discrepancia estadística importante, similar a la señalada en la nota al pie 1 .
} 
de celdas vacías señala, en primer término, la debilidad de las relaciones entre los sectores exportadores y el resto de las ramas de actividad económica, por lo que el empleo indirecto contenido en las exportaciones manufactureras - que es básicamente intersectorial (96\% del empleo indirecto contenido en las exportaciones, véase el cuadro 2) - se concentra en pocas ramas. Las excepciones notables son las exportaciones de la industria alimentaria y las de bebidas y tabaco que crean, respectivamente, 234.000 y 36.000 empleos en la agricultura (véase el cuadro A.2) y los puestos de trabajo en el sector comercio generados por las exportaciones manufactureras (479.000), de los cuales 209.000 se derivan de las exportaciones de equipo de transporte. Otro sector manufacturero exportador que genera un empleo significativo en el sector comercio es el de maquinaria y equipo (62.000 puestos de trabajo). También las exportaciones manufactureras generan 472.000 empleos en la rama de servicio de apoyo a los negocios, básicamente demandados por las exportaciones de equipo de transporte (159.000 empleos) y por las de maquinaria y equipo (63.000 empleos).

Con respecto a los siete sectores manufactureros que más empleo contienen, en el bloque inferior del cuadro 2 se descompone, entre directo e indirecto, el empleo contenido en las exportaciones manufactureras. El 47\% del empleo contenido en las exportaciones de estos sectores es directo: las exportaciones manufactureras contienen 1,06 empleos indirectos por cada empleo directo. Sin embargo, por sectores, hay diferencias notables en esta proporción. Las exportaciones de la industria alimentaria generan 4,63 empleos indirectos por cada empleo directo, lo que se deriva sobre todo de su repercusión en el empleo agrícola. Otro sector cuyas exportaciones generan elevado empleo indirecto es el de equipo de transporte (1,49 empleos indirectos por puesto de trabajo directo). En cambio, la industria electrónica, tan importante en términos de exportaciones, genera 0,35 empleos indirectos por empleo directo. Estos datos indican que las exportaciones de la industria alimentaria y de la de equipo de transporte tienen un grado de integración con la economía interna muy superior al de las del sector de la industria electrónica. Esto explica el hecho de que, no obstante que la rama de la electrónica aporta a las exportaciones manufactureras solo tres puntos porcentuales menos que la rama de equipo de transporte, la contribución de la segunda en términos de empleo exportador es 2,1 veces la de la industria electrónica.

La comparación de los datos del cuadro 2 con los del A. 3 permite detectar los cambios más importantes que se han dado en la relación entre empleo indirecto e directo contenido en las exportaciones manufactureras. Detrás de la reducción del coeficiente de empleo indirecto a empleo directo en los sectores seleccionados (de 1,21 a 1,06), en tres de las cinco ramas con peso en las exportaciones que están presentes en 2008 y 2012 este coeficiente disminuyó significativamente: en las de equipo electrónico pasó de 0,62 a 0,35; en las de equipo eléctrico, de 1,01 a 0,65 y en las de equipo de transporte, de 2,14 a 1,49; mientras que en las dos restantes se incrementó: en las exportaciones de la industria alimentaria pasó de 3,82 a 4,63 y en las de maquinaria y equipo, de 1,02 a 1,12 . Esto significa que los sectores que en conjunto aportan el 63\% de las exportaciones manufactureras, en 2012 redujeron notablemente su capacidad de generar empleo indirecto por la vía del encadenamiento con otros sectores de la economía.

\section{Exportaciones y empleo según intensidad laboral de los sectores manufactureros}

La intensidad laboral está dada por el coeficiente de empleo total (puestos de trabajo por millón de pesos de producción bruta). Los sectores manufactureros se caracterizan por una gran dispersión en cuanto a intensidad laboral. Clasificando los coeficientes de empleo por sectores en cuatro estratos: alto (superior a 4); medio-alto (entre 3 y 4); medio (de 2 a 3); medio-bajo (de 1 a 2 ) y bajo (menor a 1), en el cuadro 3 se observa la distribución del empleo manufacturero exportador según coeficiente de empleo en los años 2008 y 2012. Puede verse que la estructura exportadora del país es muy diferente de la que se deriva de los planteamientos de Heckscher-Ohlin. Los sectores manufactureros con coeficientes de empleo alto y medio-alto, o sea, los intensivos en trabajo, aportan el $4 \%$ de las exportaciones de la industria manufacturera de 2012, en las que está contenido el 15,4\% del total del empleo incorporado en ellas. En el otro extremo, más de la mitad de las exportaciones del sector proviene de las ramas con un coeficiente de empleo mediobajo, que contienen el 56\% del empleo manufacturero exportador. Si a este estrato se le añaden los sectores con bajo coeficiente de empleo se llega al $91 \%$ de las exportaciones manufactureras, que contienen el $75 \%$ del empleo incorporado en las exportaciones. Aún más, en el período considerado, la estructura exportadora del país se ha alejado del planteamiento Heckscher-Ohlin al disminuir significativamente la participación, tanto en las exportaciones manufactureras como en el empleo contenido en ellas, de los sectores intensivos en trabajo.

En dos de los cinco estratos del cuadro 3, los de coeficientes de empleo alto y medio-bajo, la relación 
entre empleo indirecto y directo es mayor que uno (1). Este último estrato, como ya se señaló, es muy relevante debido a su peso en las exportaciones manufactureras, que está fuertemente determinado por el sector de equipo de transporte, cuyo coeficiente de empleo es igual a uno (1).

CUADRO 3

México: exportaciones manufactureras y empleo según coeficiente de empleo, 2008 y 2012

\begin{tabular}{|c|c|c|c|c|c|c|c|}
\hline \multicolumn{8}{|c|}{2008} \\
\hline \multirow{2}{*}{ Coeficientes } & \multirow{2}{*}{$\begin{array}{l}\text { Exportaciones } \\
\text { manufactureras } \\
\text { (en porcentajes) }\end{array}$} & \multicolumn{3}{|c|}{ Puestos de trabajo (en miles) } & \multicolumn{3}{|c|}{ En porcentajes } \\
\hline & & Total & Directo & Indirecto & Total & Directo & Indirecto \\
\hline Alto (mayor a 4) & 3,21 & 392,0 & 108,6 & 283,5 & 10,8 & 27,7 & 72,3 \\
\hline Medio alto (3-4) & 6,00 & 497,8 & 296,1 & 201,8 & 13,7 & 59,5 & 40,5 \\
\hline Medio (2-3) & 9,32 & 492,6 & 283,6 & 208,9 & 13,6 & 57,6 & 42,4 \\
\hline Medio bajo (1-2) & 49,26 & 1647,8 & 594,1 & 1053,7 & 45,4 & 36,1 & 63,9 \\
\hline Bajo (menor a 1) & 32,21 & 602,8 & 362,4 & 240,3 & 16,6 & 60,1 & 39,9 \\
\hline Total & 100 & 3633,01 & 1644,82 & 1988,20 & 100,0 & 45,3 & 54,7 \\
\hline \multicolumn{8}{|c|}{2012} \\
\hline \multirow{2}{*}{ Coeficientes } & Exportaciones & \multicolumn{3}{|c|}{ Puestos de trabajo (en miles) } & \multicolumn{3}{|c|}{ En porcentajes } \\
\hline & (en porcentajes) & Total & Directo & Indirecto & Total & Directo & Indirecto \\
\hline Alto (mayor a 4) & 3,20 & 474,1 & 92,7 & 381,5 & 12,2 & 19,5 & 80,5 \\
\hline Medio alto (3-4) & 1,09 & 125,9 & 78,9 & 47,0 & 3,2 & 62,6 & 37,4 \\
\hline Medio (2-3) & 4,40 & 391,4 & 229,5 & 161,9 & 10,1 & 58,6 & 41,4 \\
\hline Medio bajo (1-2) & 53,67 & 2171,7 & 1042,5 & 1129,2 & 55,8 & 48,0 & 52,0 \\
\hline Bajo (menor a 1 ) & 37,64 & 729,1 & 442,1 & 287,0 & 18,7 & 60,6 & 39,4 \\
\hline Total & 100 & 3892,3 & 1885,7 & 2006,6 & 100,0 & 48,4 & 51,6 \\
\hline
\end{tabular}

Fuente: Elaboración propia sobre la base de Instituto Nacional de Estadística y Geografía (INEGI), "Matriz de insumo-producto 2008" [en línea] http://www.inegi.org.mx/est/contenidos/proyectos/cn/mip/; y "Matriz de insumo-producto 2012" [en línea] http://www.inegi.org.mx/ est/contenidos/proyectos/cn/mip12/.

\section{V}

\section{Conclusiones y lineamientos de políticas}

Entre 2008 y 2012, el empleo contenido en las exportaciones manufactureras se ha incrementado en forma significativa: entre los años considerados los puestos de trabajo contenidos en las exportaciones de la manufactura pasaron de 3,6 millones a 3,9 millones, lo que elevó su participación en el total de puestos de trabajo de la economía de 7,7\% a 9,2\%, mientras que la suma del empleo directo más el indirecto intrasectorial contenido en las exportaciones manufactureras pasó del $30 \%$ al 36,5\% de los puestos de trabajo en la manufactura reportados en la matriz.

La estructura manufacturera exportadora del país es muy diferente de la que se esperaría de los planteamientos de Heckscher-Ohlin. Si se acepta que en México el trabajo de calificación baja y media es relativamente abundante, las exportaciones manufactureras se concentran en los sectores con intensidad laboral media-baja y baja. Los sectores que hacen las mayores contribuciones a las exportaciones - equipo de transporte y electrónica - tienen coeficientes de empleo medio-bajo y bajo, respectivamente, mientras que las exportaciones intensivas en empleo -industria alimentaria - poco aportan a las exportaciones.

Sobre la base de este trabajo es posible concluir algunos lineamientos de políticas encaminadas a multiplicar el efecto empleo de las exportaciones. En este caso no se hará referencia a políticas horizontales que han sido abordadas en otros trabajos (OCDE, 2014), 
sino a planteamientos que pueden servir de marco para orientar las políticas horizontales destinadas a fortalecer la conexión entre exportaciones y empleo:

i) En el trabajo se ha mostrado que los sectores de la economía se caracterizan por diferencias notables en sus coeficientes de empleo, de tal modo que el poner énfasis en los sectores exportadores con elevada intensidad laboral relacionará más estrechamente estas variables. Entre los sectores cuyas exportaciones son importantes en términos del empleo que contienen (más de 50.000 puestos de trabajo), se destacan los siguientes sectores: industria alimentaria, bebidas y tabaco, insumos textiles, vestuario, productos de cuero, productos de minerales no metálicos y muebles, todos con un coeficiente de empleo superior a 2. En un segundo nivel están las industrias del plástico y hule, de productos metálicos y de maquinaria y equipo, con coeficientes de empleo de entre 1 y 2 .

Además del efecto directo en el empleo derivado de estas actividades, ellas tienen un efecto sustancial en la generación de empleo indirecto dentro del país, dado que la mayor parte de estos sectores se caracterizan por procesar recursos naturales de los que el país está abundantemente dotado, de manera que sus exportaciones tendrán la capacidad de generar un marcado efecto en el empleo en los sectores productores de tales recursos. Las actividades manufactureras que generan al menos un empleo indirecto por empleo directo son la industria alimentaria, bebidas y tabaco, insumos textiles, plástico y hule y metálica básica. Por lo tanto, una política que enfatice en las exportaciones de estos productos tendrá un efecto sensible en el empleo agrícola y minero por vía indirecta. Para que la conexión entre estos sectores efectivamente se cristalice, la política debe orientarse a mejorar la eficiencia de las empresas productoras de materias primas, de modo que estén en condiciones de cumplir con los requisitos de calidad demandados por las actividades exportadoras.

ii) Es conocido el hecho de que las empresas medianas y pequeñas se caracterizan por tener coeficientes de empleo más elevados que las grandes. Esto ha conducido a que, para potenciar el efecto empleo de las exportaciones, en las políticas se haya buscado transformar estas empresas en directamente exportadoras. Desde el punto de vista del presente trabajo, se requiere cambiar el énfasis en estas políticas a partir del hecho de que las empresas no solo pueden dedicarse a vender su producción en el exterior, sino que también pueden ser indirectamente exportadoras por la vía de la producción de insumos para las actividades directamente exportadoras. La agricultura es un sector en que los pequeños productores son muy numerosos, en consecuencia, una política que estimule su conexión con las empresas que procesan y comercializan sus productos de exportación tendrá un notable efecto indirecto en el empleo agrícola. Esto también requiere la transformación de la pequeña agricultura a fin de dotarla de las capacidades para integrarse en estas cadenas de valor.

iii) Debido al gran peso que la industria ensambladora tiene en las exportaciones del país, la que se caracteriza por su elevado contenido de importaciones, las políticas industriales han hecho hincapié en el desarrollo de la producción de partes y componentes. De alcanzarse este propósito, se incrementará el empleo indirecto generado por estas exportaciones. El mejor ejemplo de esto lo constituye la industria electrónica, con el $28,9 \%$ de las exportaciones manufactureras en 2003 (Fujii y Cervantes, 2013), que es la rama con los coeficientes de empleo por unidad de producción y de empleo indirecto por cada empleo directo más reducidos. Aumentar la producción interna de partes y componentes electrónicos plantea desafíos muy complejos, pues esta industria electrónica está integrada en una cadena global de valor que se caracteriza por una profunda fragmentación internacional, en la que la decisión sobre el lugar de cada país en el proceso productivo es tomada por las empresas que encabezan las cadenas sobre la base de las ventajas de los diversos países para la producción de las partes y el desarrollo de cada una de las fases del proceso productivo. Por consiguiente, esta vía no solo está sujeta a decisiones nacionales, sino que estas deben enmarcarse en los criterios que guían a las empresas para fragmentar internacionalmente la producción.

Otra veta orientada a ampliar el efecto empleo de la producción en el marco de las cadenas globales de valor se basa en el hecho de que para que un producto llegue a manos del consumidor necesita pasar por diferentes fases que, en muchos casos, comprenden las etapas de investigación y desarrollo (I+D), diseño del producto, operaciones de logística para la producción y compra de materiales, partes y componentes, ensamble de las partes, logística para la distribución del producto, comercialización y servicios postventa. Estas fases se pueden encontrar 
en productos tecnológicamente simples, como vestuario, por ejemplo, y en productos intensivos en tecnología, tales como equipos electrónicos y de transporte. En otros productos, como la producción de material siderúrgico, esta cadena puede ser más corta.

De muchas de estas actividades se ocupan empresas específicas, algunas de cuyas actividades también pueden ser subcontratadas dando origen a una densa red de empresas en torno de una cadena. Entonces, en el contexto del problema aquí abordado, hay que explorar la posibilidad de que empresas nacionales se inserten en actividades específicas de las cadenas mundiales de valor en el sentido más amplio del término y, en el caso de que existan, definir políticas industriales específicas para potenciarlas.

En las cadenas de valor también se integran actividades de servicios, lo que abre la posibilidad de que empresas de este sector se expandan en el marco de las cadenas. Una de estas actividades es el transporte, que se caracteriza por estar dominado por empresas medianas y pequeñas, lo que fundamenta la necesidad de políticas encaminadas a la modernización de las empresas de transporte y logística.

iv) Como se señala en CEPAL (2013, pág. 167), los efectos sobre el empleo son cuantitativamente diferentes según los mercados de destino de las exportaciones. Con respecto a América Latina, se señala que las exportaciones más intensivas en trabajo son las dirigidas a la misma región y a los Estados Unidos de América. Es sabido que las exportaciones mexicanas están dirigidas sobre todo a los Estados Unidos de América y, en un muy lejano segundo lugar, al Canadá. Por lo tanto, para México, diversificar sus mercados de exportación hacia el sur del continente tendrá efectos positivos en el empleo.

v) Del éxito de las políticas micro y mesoeconómicas dirigidas a potenciar el efecto empleo de las exportaciones se derivará un efecto multiplicador positivo en el plano macroeconómico. El aumento del empleo contenido en las exportaciones se traducirá en un incremento del valor agregado interno contenido en las exportaciones, lo que estimulará la demanda agregada y, por lo tanto, el producto y el empleo agregados. 


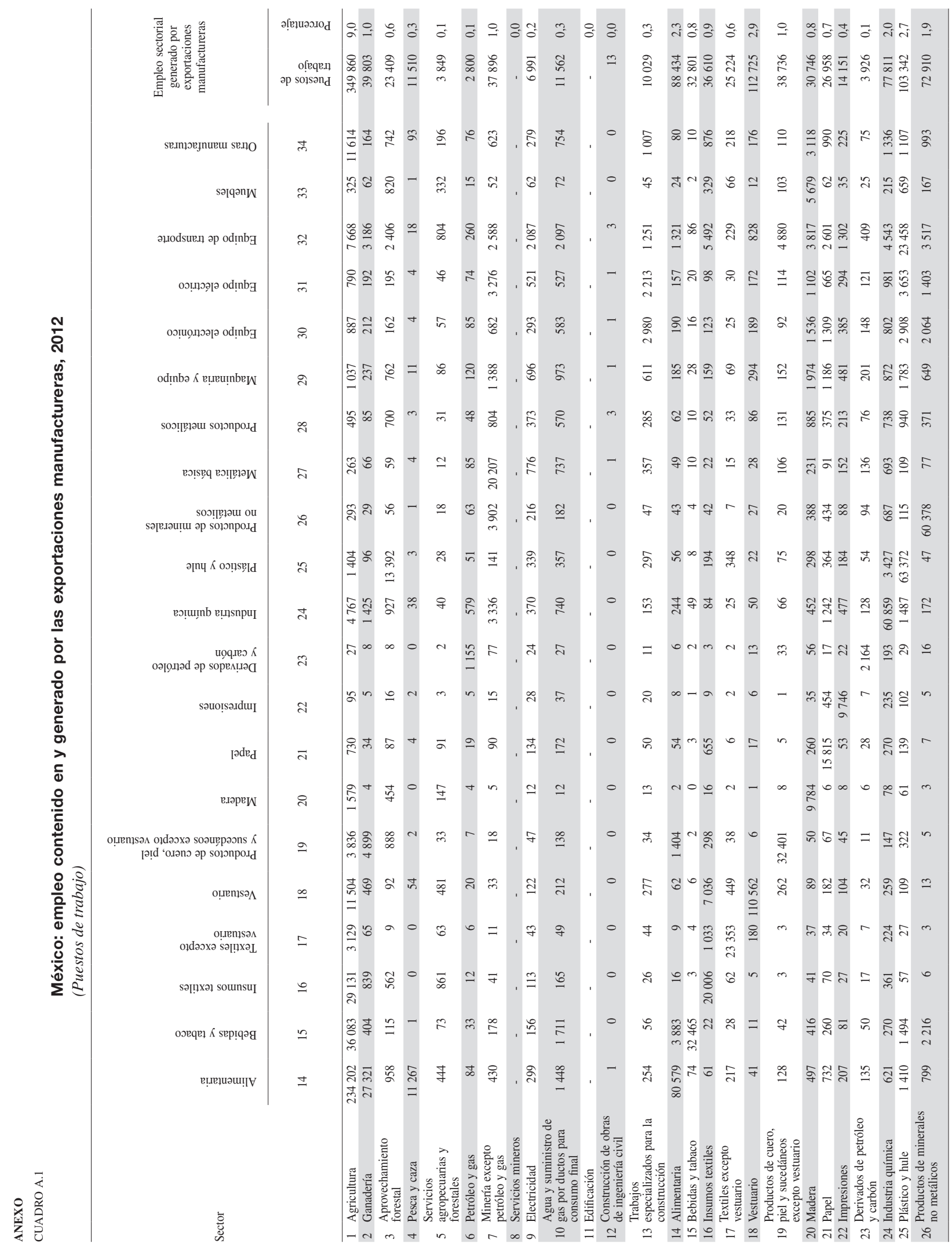




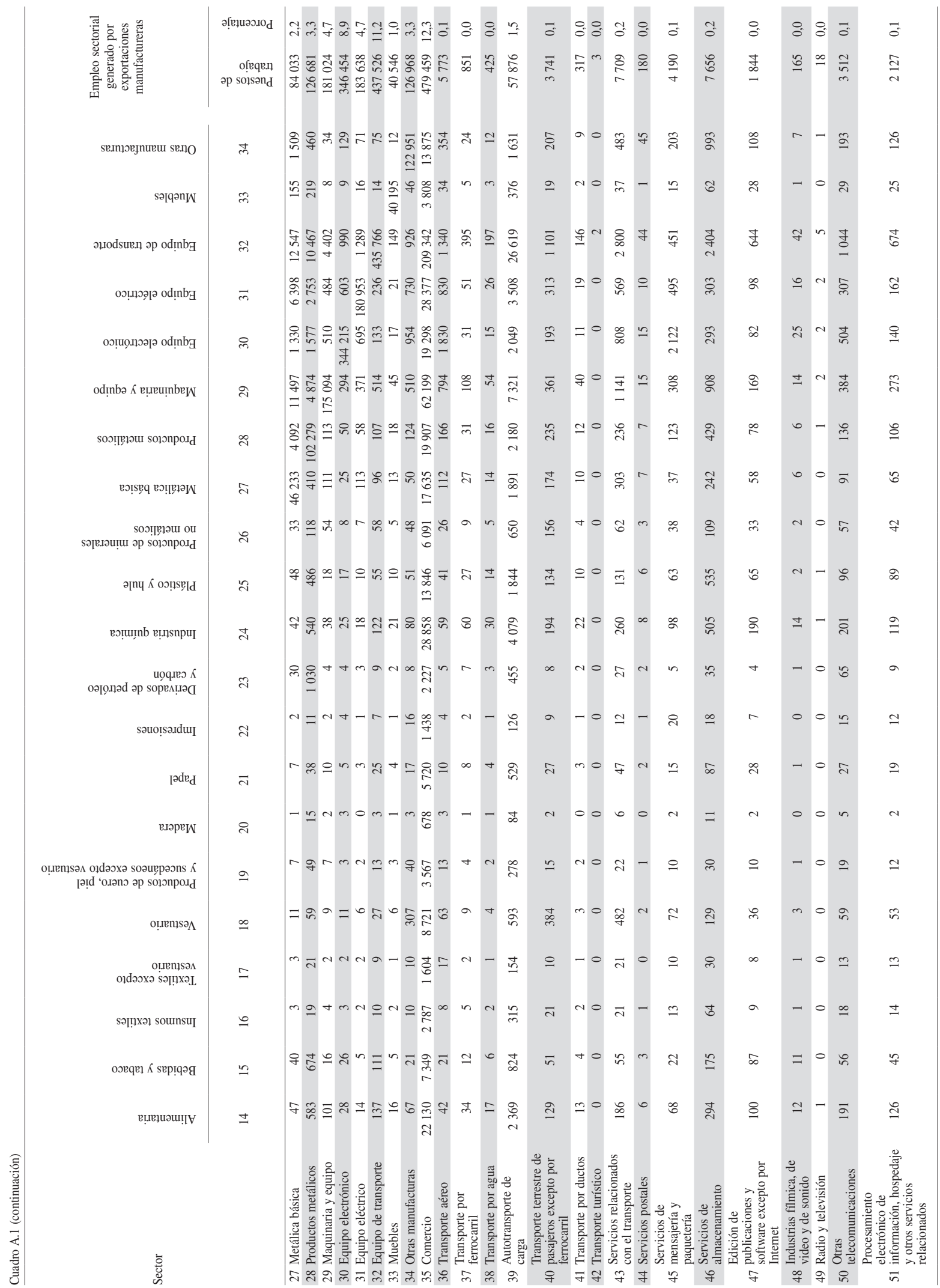




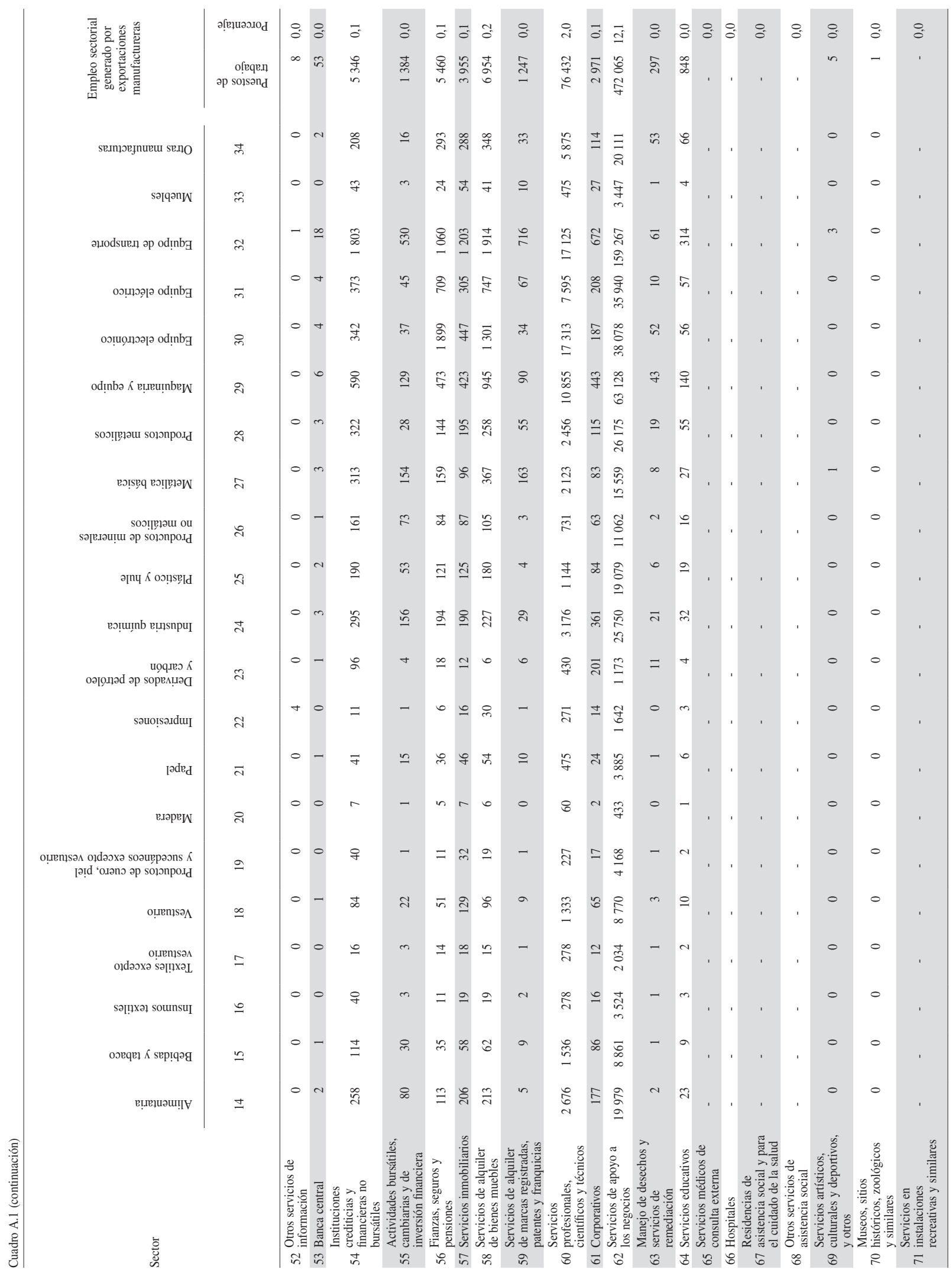




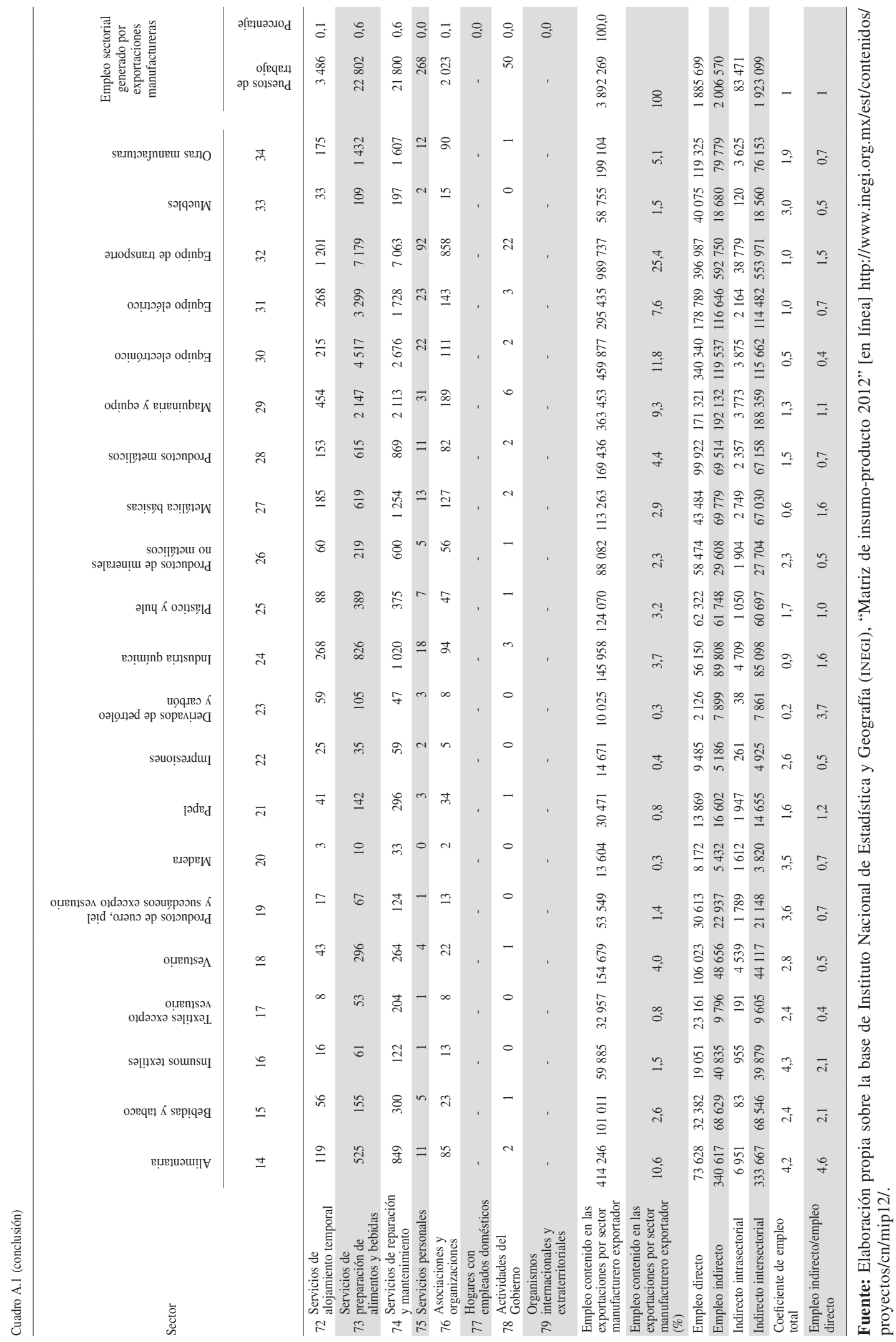




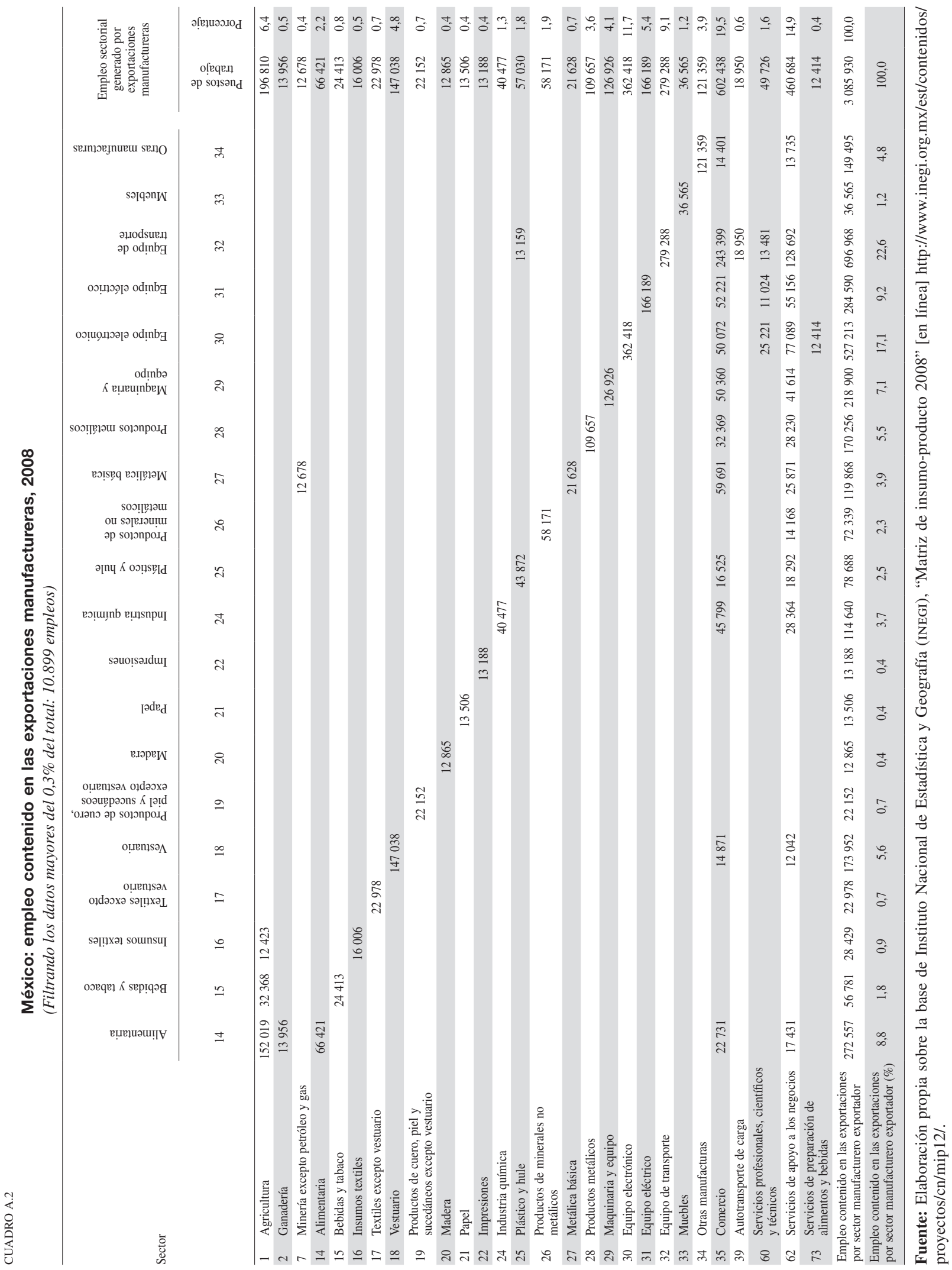



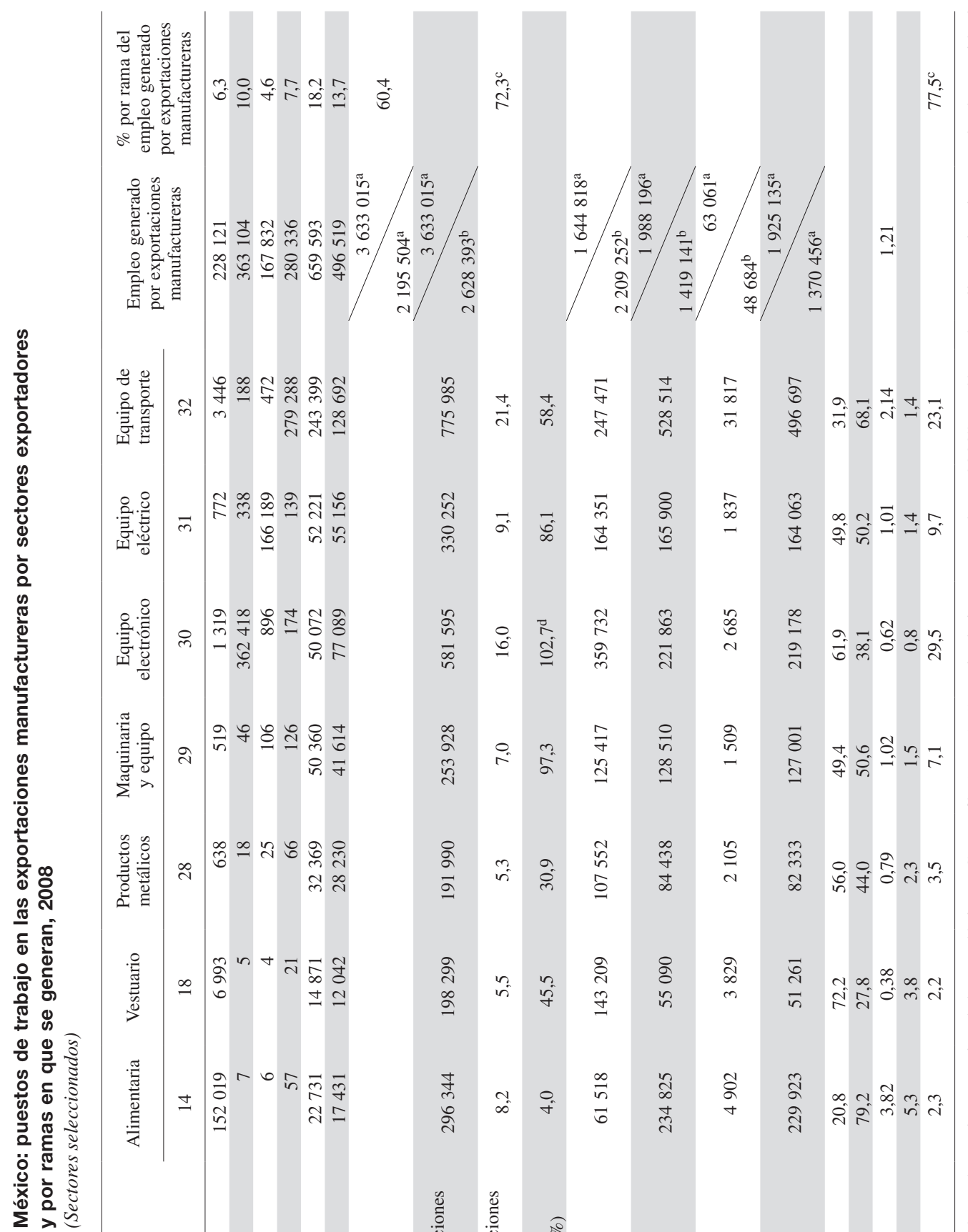

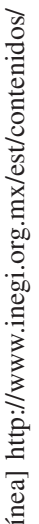

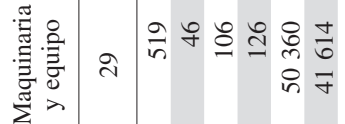

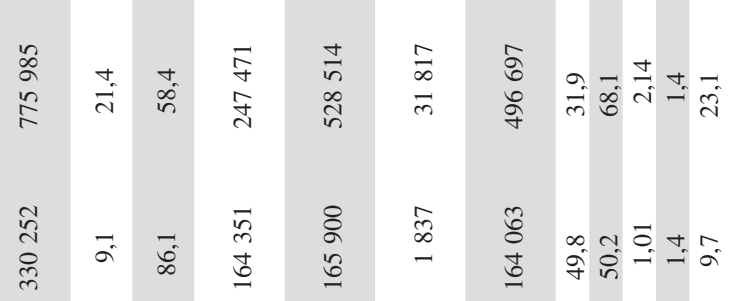

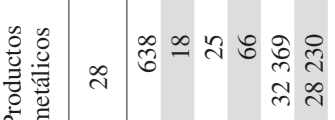

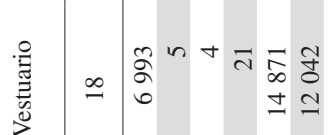

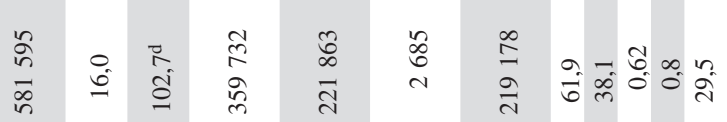

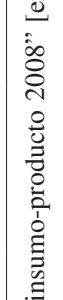
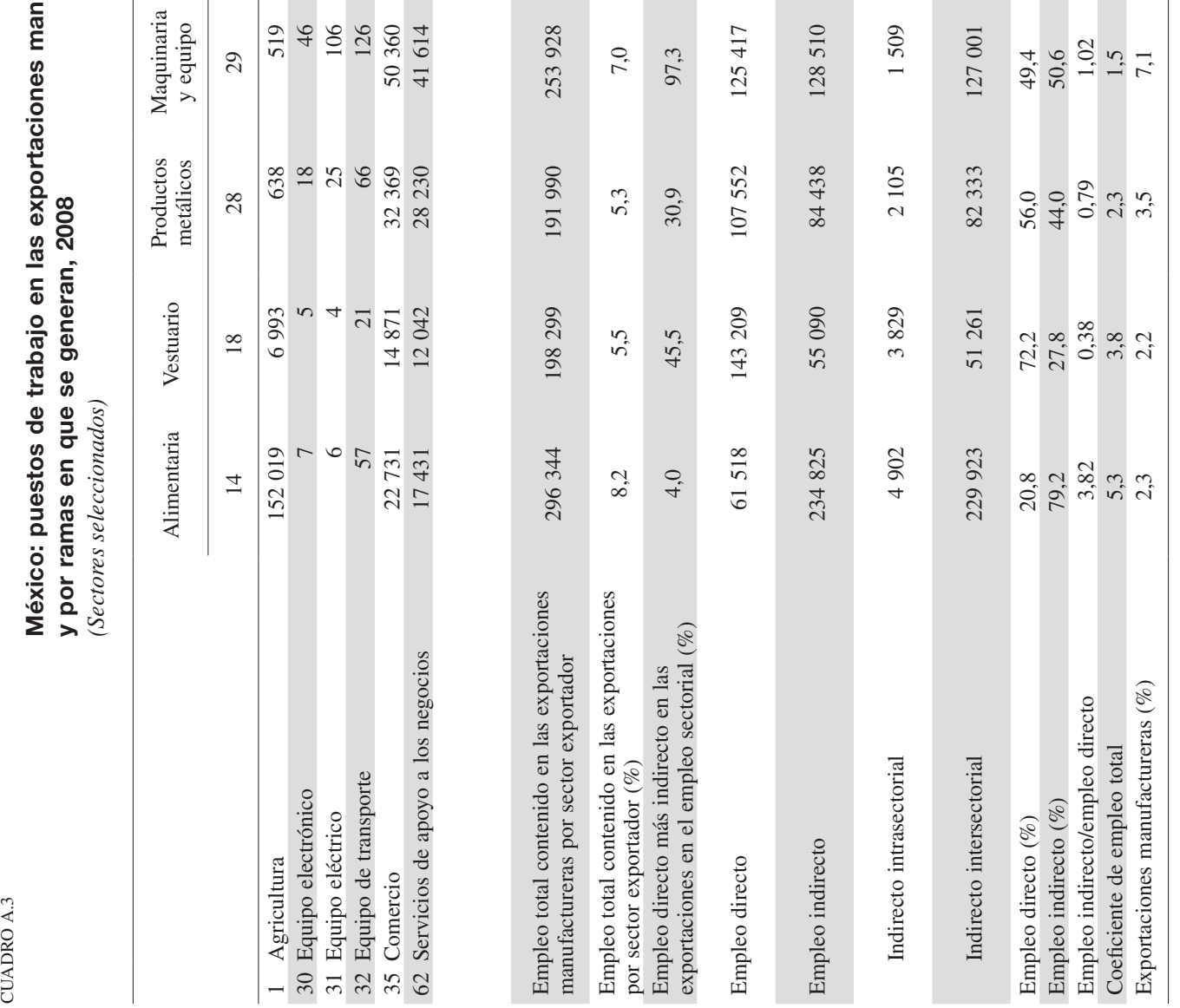

苞
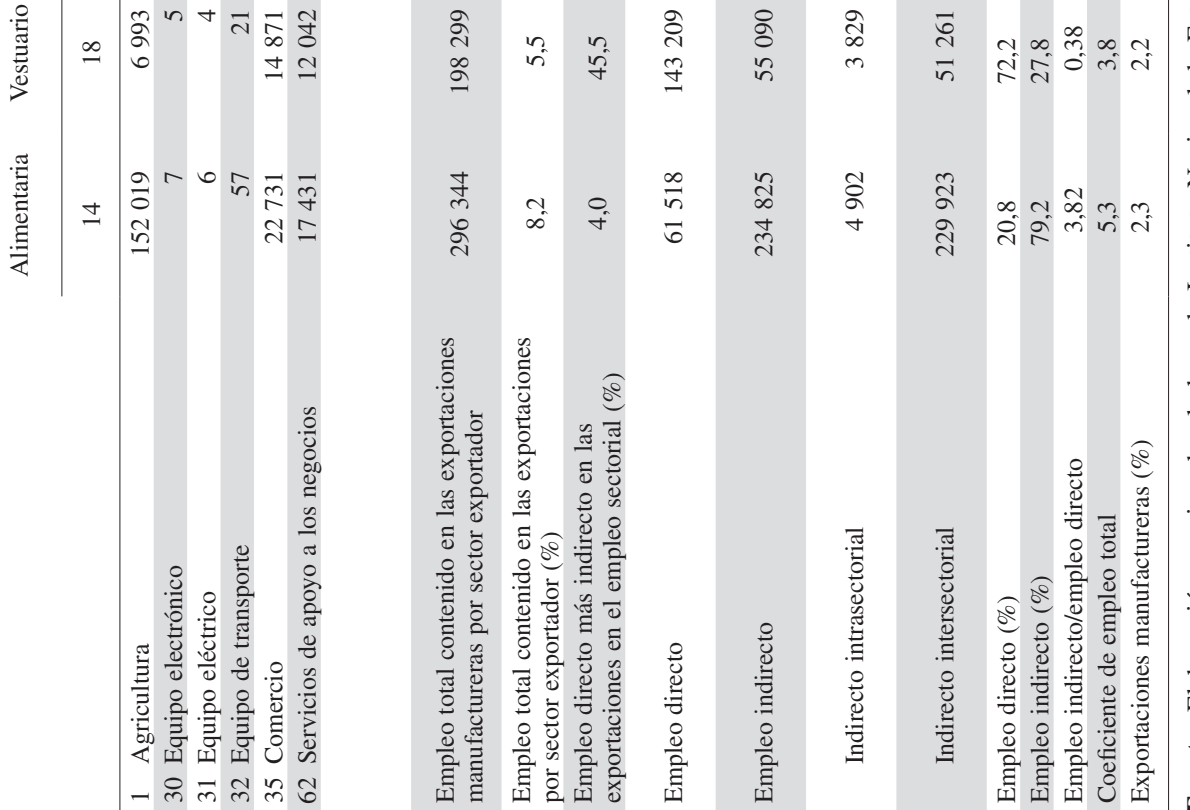

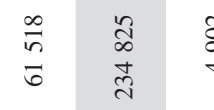

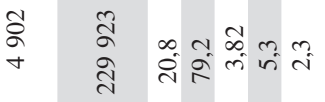

可

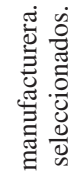

范

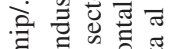
है. 至 8

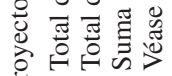




\section{Bibliografía}

Aswicahyono, H., D. Brooks y C. Manning (2011), "Exports and employment in Indonesia. The decline in labor-intensive manufacturing and the rise in services", Asian Development Bank Working Paper Series, $\mathrm{N}^{\circ} 279$, Banco Asiático de Desarrollo.

Banco de México (2013), Informe anual 2012, Ciudad de México.

Brautzsch, H.-U. y U. Ludwig (2011), "International fragmentation of production and the labour input into Germany's exports. An input-output analysis", IWH Discussion Papers, $\mathrm{N}^{\circ} 14$, Halle Institute for Economic Research.

Cardero, M.E. y F. Aroche (2008), "Cambio estructural comandado por apertura comercial. El caso de la economía mexicana", Estudios Económicos, vol. 23, № 2, Ciudad de México, El Colegio de México.

Cepal (Comisión Económica para América Latina y el Caribe) (2013), Comercio internacional y desarrollo inclusivo. Construyendo sinergias (LC/G.2562), Santiago.

Cervantes, R. y G. Fujii (2012), "The Mexican trade liberalization process and its net effects on employment: 1988-2004", EconoQuantum, vol. 9, $\mathrm{N}^{\circ}$ 2, Universidad de Guadalajara.

Chen, X. y otros (2012), "Domestic value added and employment generated by Chinese exports: a quantitative estimation", China Economic Review, vol. 23, № 4, Amsterdam, Elsevier.

Fujii, G. y R. Cervantes (2013), "México: valor agregado en las exportaciones manufactureras", Revista CEPAL, $\mathrm{N}^{\circ} 109$ (LC/G.2556-P), Santiago, Comisión Económica para América Latina y el Caribe (CEPAL).

Hufbauer, G.C. y J. Schott (1993), NAFTA: An Assessment, Washington, D.C., Peterson Institute.

INEGI (Instituto Nacional de Estadística y Geografía) (2014), Balanza comercial de mercancías de México. Anuario estadístico 2013. Exportaciones pesos, Ciudad de México.

(2012), Encuesta Nacional de Ocupación y Empleo 2012, Ciudad de México.
Irawan, T. y P.J.J. Welfens (2014), “Transatlantic trade and investment partnership: sectoral and macroeconomic perspectives for Germany, the EU and the Us", IZA Policy Paper, $\mathrm{N}^{\circ} 78$, Bonn.

Kiyota, K. (2011), "Trade and employment in Japan", OECD Trade Policy Papers, $\mathrm{N}^{\circ} 127$, oECD Publishing.

Koller, W. y R. Stehrer (2010), "Trade integration, outsourcing and employment in Austria: a decomposition approach", Economic Systems Research, vol. 22, $\mathrm{N}^{\circ}$ 3, Taylor \& Francis.

Kupfer, D. y otros (2013), "Different partners, different patterns. Trade and labour market dynamics in Brazil's post-liberalization period", OECD Trade Policy Papers, $\mathrm{N}^{\circ} 149$, oECD Publishing.

Los, B., M. Timmer y G. de Vires (2012), "China and the world economy: a global value chain perspective on exports, incomes and jobs", GGDC Research Memoranda, $\mathrm{N}^{\circ} 128$.

Lurweg, M., J. Oelgemöller y A. Westermeier (2010), "Sectoral jobs effects of trade: an input-output analysis for Germany", CAWM Discussion Paper, $\mathrm{N}^{\circ} 19$.

Lustig, N., B. Bosworth y R. Lawrence (1993), "El impacto del libre comercio en América del Norte”, Economía Mexicana, vol. 2, número especial, Ciudad de México, junio.

Naciones Unidas (2014), UN Comtrade Data Base [en línea] comtrade.un.org.

OCDE (Organización para la Cooperación y el Desarrollo Económicos) (2014), Interconnected Economies: Benefiting from Global Value Chains, París.

Ruiz-Nápoles, P. (2004), "Exports, growth, and employment in Mexico, 1978-2000", Journal of Post Keynesian Economics, vol. $27, \mathrm{~N}^{\circ} 1$, M.E. Sharpe.

Sousa, N. y otros (2012), "Extra-EU exports and employment", Chief Economist Note, $\mathrm{N}^{\circ} 2$, Comisión Europea.

Wood, A. (1994), North-South Trade, Employment and Inequality: Changing Fortunes in a Skill-Driven World, Oxford, Clarendon Press. 